\title{
Technology for the People? Humanity as a Compass for the Digital Transformation
}

\begin{abstract}
How do we define what technology is for humans? One perspective suggests that it is a tool enabling the use of valuable resources such as time, food, health and mobility. One could say that in its cultural history, humanity has developed a wide range of artefacts which enable the effective utilisation of these resources for the fulfilment of physiological, but also psychological, needs. This paper explores how this perspective may be used as an orientation for future technological innovation. Hence, the goal is to provide an accessible discussion of such a psychological perspective on technology development that could pave the way towards a truly human-centred digital transformation.
\end{abstract}

\begin{abstract}
Definitions of 'psychology' as a science usually include four components: the description, explanation, prediction and change of human behaviour and experience. Descriptions bring order and structure by defining fundamental dimensions and categories that can account for variance in phenomena (i.e. signals that can be sensed by humans - or by machines). Building upon these, explanations provide causal chains (e.g. $X$ increases the likelihood of $Y$; probabilistic causation), which are needed for data-based prognoses, allowing for predictions of future states. Ultimately, the three lead to measures and interventions which seek to change behaviour and experience.
\end{abstract}

In other words: psychological methodology allows humans to understand which variables lead to possible ideal

(C) The Author(s) 2020. Open Access: This article is distributed under the terms of the Creative Commons Attribution 4.0 International License (http://creativecommons.org/licenses/by/4.0/).

Open Access funding provided by ZBW - Leibniz Information Centre for Economics.

Prof. Dr. rer. nat. Thomas Franke is Full Professor, Engineering Psychology and Cognitive Ergonomics, Institute for Multimedia and Interactive Systems, University of Lübeck.

Mourad Zoubir, M Sc., is Research Associate, Engineering Psychology and Cognitive Ergonomics, Institute for Multimedia and Interactive Systems, University of Lübeck. human states, or at least away from dysfunctional states. But what role can psychology play in determining the direction of the digital transformation?

Is digitalisation a utopia or a dystopia?

Before further examining the role of psychology, it is perhaps worthwhile to understand which future technological states are possible. While realistic future states of digitalisation are difficult to determine, both optimistic and pessimistic perspectives of the future can be used to explicate a range of human needs, desires and fears.

On the one hand, digitalisation can be described as a utopia that promises an increased quality of life, with digital tools which, for instance, could provide or enable equal educational opportunities for all, mobility everywhere, a universal basic income and the promise of never having to work again (e.g. in the sense of wage labour).

This image can be contrasted with a dystopia. In 20 years, will most jobs be dominated by artificial intelligence (AI)? Not only relatively routine tasks like assembly line work or truck driving, but also seemingly complex tasks; such as cognitive work based on rich data and pattern-based decision making, e.g. in the banking sector, in insurance companies, or within public administration. Already, trained Al can detect breast cancer up to five years in advance, with reduced risk of biases caused by individual factors (such as race) that humans are subject to. ${ }^{1}$

Shared first authorship.

1 A. Conner-Simmons, R. Gordon: Using Al to Predict Breast Cancer and Personalize Care, in: MIT News, 2019, http://news.mit.edu/2019/ using-ai-predict-breast-cancer-and-personalize-care-0507 (3.1.2020). 
Could self-optimising Al exceed human intellectual capacity and take advantage of the internet of things in 40 years' time, with its widespread implementation of sensors $?^{2}$ Revoking a state of the world where humans once enjoyed a certain degree of privacy in a natural environment of transient analogue signals (e.g. light and sound waves) that only they could decode at a given time and place with their sensory capabilities (i.e. human senses); with signals that now can be perceived, stored, understood and experienced in much higher fidelity by machines?

While Al may possibly still suffer from disembodiment, given the lower flexibility and mobility - and therefore its reduced ability to assess signals from the natural world (i.e. dependency on motivating humans to carry, locomote and position Al sensor interfaces, e.g. in car driving or smartphone usage), could these disadvantages of Al be offset by other properties still leading to superior cognitive abilities? That is, on the one hand, by ultra-fast mobility in a global data network, coupled with sufficient information storage capacity for a quasi-infinite long-term memory. On the other hand - to quote a central proverb of psychology - past behaviour is the best predictor of future behaviour; a fully accessible library of the past could be used to reliably predict future events. ${ }^{3}$ Hence, could a disembodied $\mathrm{Al}$, that is less restricted by the constraints of space and time to which humans are subject, be a powerful - and difficult to control - data weapon?

And finally, while today robots are often still constrained by factors such as terrain or limited energy storage (i.e. autonomy/range), could - perhaps in 60 years - an Al be physically equal (or even superior) to humans, finally making the differentiation between coexisting natural and artificial intelligences extremely difficult or even impossible?

This hypothetical juxtaposition suggests that while there may be hope for digitalisation to improve the quality of human life, at the same time, one key fear could be the loss of sovereignty towards humanity's digital creations.

\section{Digital sovereignty as a key societal challenge}

Ultimately, any prediction about the timing and nature of complex technical innovations should be taken with a measure of caution. However, by examining current de-

2 M. Hossain, M. Fotouhi, R. Hasan: Towards an Analysis of Security Issues, Challenges, and Open Problems in the Internet of Things, in: IEEE World Congress on Services, 2015, pp. 21-28.

3 K. Radinsky, E. Horvitz: Mining the Web to Predict Future Events, in: Proceedings of the Sixth ACM International Conference on Web Search and Data Mining, Association for Computing Machinery, 2013, pp. 255-264. velopments, we can already extrapolate future challenges to digital sovereignty, which can be defined as the selfcontrolled, self-determined action of humans with regard to the use of digital media. ${ }^{4}$

The issue of data security alone suggests some possible challenges. For example, surveys show that $37 \%$ of Germans use the same passwords for several online services. ${ }^{5}$ This is a dangerous practice, as databases containing logins and passwords are regularly breached and uploaded publicly (e.g. Collections \#2-5, with approximately 2.2 billion individual users' data). ${ }^{6}$ How many people still use the first email address they created, without ever having changed their password? Even without hacking, personal data may still be vulnerable: according to the Identity Leak Checker, the most-used password is 123456; the second-most-used password is $123456789 .^{7}$ Both findings suggest a carefree attitude towards digital security, contrary to the idea of digital sovereignty.

This issue of protection of personal information against unwanted access can be contrasted with the voluntary dispersion of personal data on social media, which can also be used against their own users. For example, social media posts can be used by criminals to identify potential burglary targets. ${ }^{8}$ At the same time, user data can also be used for less nefarious purposes. For example, in the German TV Show, "Let yourself be monitored" (Lass dich überwachen), the show master Jan Böhmermann confronted audience members with content from their own social media accounts for the entertainment of viewers, for instance resulting in one audience member losing a 'quiz show' about their own personal life against an employee of the show, who had been trained using data from their social media. ${ }^{9}$

4 bitkom: Digitale Souveränität: Positionsbestimmung Und Erste Handlungsempfehlungen Für Deutschland Und Europa. Bundesverband Informationswirtschaft, Telekommunikation und neue Medien e. V., 2015, https://www.bitkom.org/Bitkom/Publikationen/Digitale-Souveraenitaet-Positionsbestimmung-und-erste-Handlungsempfehlungen-fuer-Deutschland-und-Europa.html (3.1.2020).

5 bitkom Research: Jeder Dritte nachlässig bei Passwortwahl, Bundesverband Informationswirtschaft, Telekommunikation und neue Medien e.V., 2016, https://www.bitkom.org/Presse/Presseinformation/ Jeder-Dritte-nachlaessig-bei-Passwortwahl.html (3.1.2020).

6 Hasso Plattner Institut: 2,2 Mrd. E-Mail-Adressen mit Passwörtern aus jüngsten Collection-Datenleaks eingepflegt, 2019, https://hpi.de/ pressemitteilungen/2019/hpi-identity-leak-checker-22-milliarden-email-adressen-mit-passwoertern-aus-juengsten-collection-datenleaks-eingepflegt.html (3.1.2020).

7 Hasso Plattner Institut: Identity Leak Checker, 2019, https://sec.hpi. de/ilc/statistics (3.1.2020).

8 C. Rose: The Security Implications Of Ubiquitous Social Media, in: International Journal of Management \& Information Systems (IJMIS), Vol. 15, No. 1, 2011.

9 ZDF: Lass dich überwachen!, 2019, https://www.zdf.de/uri/ b055b1bb-3fa1-46c9-b919-89aa66fc4420 (3.1.2020). 
These examples illustrate how trait-based (i.e. dispositional/stable) or state-based (i.e. situational/variable) carelessness can influence the future of digitalisation and indicate how behavioural factors can define the framing conditions of digital sovereignty. At the same time, other perhaps even more fundamental human factors should not be disregarded in their ability to set the boundaries of possible progressions of the digital transformation.

\section{We live in an attention economy}

Smartphone usage is a good example of how physiological, cognitive and emotional factors come together in digitalisation. While the broader introduction of our current primary phenotype of mobile computing devices (i.e. modern smartphones) began about ten years ago (i.e. iPhone launched in 2007, HTC Dream as first commercial Android device launched in 2008), today, smartphones are already extremely widespread: in Germany, market penetration is approximately $79 \%$ of the population. ${ }^{10}$ With functions ranging from educational apps for small children to health apps for seniors, every smartphone arguably has the potential to raise the standard of living for its users. ${ }^{11}$ At the same time, it can be argued that smartphones make people unhappy: Twenge et al. showed that the psychological well-being of teenagers has, on average, decreased since the widespread increase of screen-time. ${ }^{12}$ Furthermore, even if smartphones do increase happiness, can it be said that this is achieved without a loss of autonomy (e.g. less active intentional usage decisions or less self-determined control of data transactions)?

For example, Andrews et al. interviewed a group of 18-33-year-olds about their mobile phone usage behaviour. ${ }^{13}$ Participants estimated that, on average, they checked their mobile phones about 37 times a day. This estimate was then compared with data logging of actual usage. Here, a large underestimation was shown; participants checked their mobile phones about 85 times a day on average, with a total of use time of roughly six hours a day.

10 newzoo: Global Mobile Market Report, 2018, https://newzoo.com/ insights/rankings/top-countries-by-smartphone-penetration-andusers/ (3.1.2020).

11 S. Griffith, M. Hagan, P. Heymann, B. Heflin, D. Bagner: Apps As Learning Tools: A Systematic Review, in Pediatrics, Vol. 145, No. 1, 2020; M. Changizi, K. Mohammad: Effectiveness of the MHealth Technology in Improvement of Healthy Behaviors in an Elderly Population Systematic Review, in: MHealth, Vol. 3, 2017.

12 J. Twenge, G. Martin, W. Campbell: Decreases in Psychological WellBeing among American Adolescents after 2012 and Links to Screen Time during the Rise of Smartphone Technology, in: Emotion, Vol. 18, No. 6, 2018, pp. 765-780.

13 S. Andrews, D. Ellis, H. Shaw, L. Piwek: Beyond Self-Report: Tools to Compare Estimated and Real-World Smartphone Use, in: PLOS ONE, Vol. 10, No. 10, 2015.
While this discrepancy between estimated and actual smartphone usage has many potential components (e.g. possible limited memory for routine actions), the findings in regard to the amount of smartphone checks is important as it indicates a desire for participants to regularly monitor their phones, a task which could hamper the fulfilment of other daily duties.

One primary human function is information processing. As described in the field of engineering psychology by Wickens et al., in human technology interaction contexts, information is taken from the environment (perception), evaluated - including decision-making on subsequent actions - (cognitive processing), and finally, acted upon accordingly (action control). ${ }^{14}$ However, all of these components are dependent on limited cognitive resources (e.g. attention resources or working memory resources).

For example, visual focus in the human eye is only at a maximum in a small area, the fovea. In order to perceive one's surroundings, constant jumps between elements in the visual field are used..$^{15}$ Equally limited is situation awareness (i.e. how perceived elements within an environment are related to one another and used to make predictions about future states of the environment), which is constrained by working memory, which can only process a certain number of information elements at the same time. ${ }^{16}$ Taken altogether, these examples indicate that humans must constantly make decisions about what information to focus visual and cognitive attention on and that this attention is the fuel for information processing.

In the context of digitalisation, attention may further become a key resource, as only one information element can be displayed in the foreground of a visual interface at any given moment. In other words: only if a respective app is visible on a display can app operators supply information to human users via the visual sensory channel (i.e. screen limitations). This incentivises a competition between different digital platforms for attention, thereby promoting applications that try to prioritise attention over other alternatives (be it on an interface or not), so that focus is retained, for example, on marketable content.

These arguments, taken together with the study by Andrews et al., which demonstrates that media use is sometimes unconscious and possibly without reflection, imply that this 'attention economy' can become a challenge

14 C. Wickens, J. Hollands, S. Banbury, R. Parasuraman: Engineering Psychology and Human Performance, New York 2015, p. 33.

15 O. Braddick: Neural Basis Of Visual Perception, in: J. Wright (ed.): International Encyclopedia of the Social \& Behavioral Sciences (Second Edition), 2015, pp. 184-190.

16 C. Wickens, J. Hollands, S. Banbury, R. Parasuraman, op. cit., p. 353. 
when safety-relevant behaviour should be prioritised (e.g. in road traffic). Some interventions seek to counteract negative consequences of digital development. Advertising campaigns by (1) radio stations (e.g. NDR) in reaction to a growing number of fatal smartphone-induced traffic accidents, regularly remind listeners that their "smartphone can wait", or (2) insurance companies (e.g. DAK) reacting to health concerns, appealing to users to take a break from their smartphones and social media platforms. ${ }^{17}$ These examples can also be used to underline that the digital transformation must be actively shaped and driven - but by whom?

\section{Humans as shapers of the digital transformation?}

The previous sections can be used to surmise two potential paradigms which could be used to describe at least two ends from which to start digitalisation: the digital transformation could be (a) driven by innovation (i.e. technological possibilities) or (b) driven by society (i.e. human needs). While this is a very basic differentiation (i.e. further alternatives or hybrid forms are conceivable), as a thought experiment it points to a central question: what role should humanity play in the digital transformation?

Examining the one extreme, innovation as the motor of digitalisation can be described as always doing whatever is feasible. One challenge in this paradigm is the allocation of roles. While companies seek out ever more profitable inventions which - in the best case - make everything better, concurrently, society is assigned the task of avoiding possible negative side-effects of the innovations. In other words, a technology is developed, and its merits and potential harm are discussed ex post facto. In such a distribution of roles, situations can arise where citizens express perceptions such as: "We [the general public] can't influence that anyway", "A solution will be found eventually" or "If we don't do it, someone else will". These possibly indicate a diffusion of responsibility or a learned helplessness - i.e. a feeling of powerlessness in the face of a (possibly overwhelming) digital transformation. Hence, this worst case scenario can lead to a passive societal perspective on the digital transformation.

So, what is a possible, opposing best case? Perhaps it is a digitalisation that follows only the needs of its users; i.e. doing that which is desirable, by increasing participation of the general public in the development - and the profits of - the digital transformation. Here, society is the motor

17 NDR: Kopf Hoch. Das Handy Kann Warten, 2019, https://www.ndr. de/leben/Kopf-hoch-Handy-kann-warten.html (3.1.2020); DAK: Mit diesen Tricks manipuliert dich dein Smartphone, 2019, https://gesundes-miteinander.de/mit-diesen-tricks-manipuliert-dich-dein-smartphone/ (3.1.2020). of the digital transformation, inspiring questions such as "How do we wish to live?" or "What do we really need?", and thereby taking an active role in the progress of technological innovation. In other words: by putting society in the centre of the technological design process, the digital transformation begins with defining needs rather than chasing possibilities.

Perhaps this second paradigm leads away from dystopian and utopian future states and towards ethically grounded, gradual transformation, in the sense of ethicsby-design. ${ }^{18}$ From this perspective, the greatest barrier to the digital transformation would then be the final element of the innovation trifecta: viability - that which is economically or politically possible.

So, in summary, these two hypothetical and extreme examples suggest that instead of asking, for example, "What shall society do when Al spreads everywhere?", the question should be "Which future Al does society want or need?". As a consequence, the compass for digital innovations should be developed and set today, by scientists, developers, politics and the general citizenry through intensive discussion and reflection of possible paths of technological developments and - most importantly - of human needs.

\section{Creating a navigation toolkit for a "good" digital transformation}

If an innovation paradigm driven by human needs is accepted, the key question "How do we wish to live?" must not only be answered; its answer must consequently also be implemented. There are many possible approaches to garner citizen participation in the development of specific digital technologies - not the least of which is humancentred design. ${ }^{19}$ However, to implement human needs generally, i.e. to bring about a complex paradigm shift of digital innovation, a set of guidelines are needed. These guidelines should serve as a compass (or rather - because of their complexity - as an entire navigation toolkit) for all experts who wish to bring digitalisation forward.

What could this toolkit include? The following elements appear to be key:

18 V. Dignum, M. Baldoni, C. Baroglio et al.: Ethics by Design: Necessity or Curse?, in Proceedings of the 2018 AAAI/ACM Conference on Al, Ethics, and Society, Association for Computing Machinery, 2018, pp. 60-66.

19 J. Giacomin: What Is Human Centred Design?, in: The Design Journal, Vol. 17, No. 4, 2014, pp. 606-623. 
1. Models. What can be considered "desirable" or "advantageous" for individuals, specific groups and for society as a whole?

2. Metrics. How can desirable digitalisation be made measurable? What are the key measurable dimensions (i.e. variables)? How can such metrics enable the accurate appraisal and selection of actions, based on their suitability for individual and societal needs?

3. Performance indicators. How can these variables be aggregated to form usable indicators of the progress of a human-centred digital transformation (i.e. for monitoring, benchmarking and further data-driven evaluation purposes)?

4. Simplification tools. How can such key performance indicators (KPIs) be conveyed in a manner that fulfils the needs of the stakeholders? For example: Which visualisations (e.g., in a management dashboard application) are both intuitive and informative, thereby reducing the required workload to manage the progress?

Hence, of particular interest is, to specify which metrics and KPIs should be used in a navigational toolkit for a 'good' digital transformation.

\section{When does technology make us happy?}

It can be argued that a necessary axiom for digitalisation is that, above-all, it is meant to serve humans. As such: the benefits of a technology must outweigh its costs. But how can a benefit be measured?

Continuing the approach started above, a benefit can be defined as a partial or full satisfaction of a human need and this satisfaction can be achieved by making key resources accessible - with resources being defined as anything which can be used to achieve a goal, such as money, time or mobility. ${ }^{20}$ All resources can be regulated by humans using the same fundamental psychological principles, described e.g. in behavioural economics. For example, prospect theory describes the expected acquisition of resources (i.e. resource gains relative to the subjectively perceived reference point) that leads to positive emotions, while the expected loss of resources leads to negative emotions. ${ }^{21}$ Yet, humans are not completely rational in their resource-related decision-making. For ex-

20 S. Feldman, M. Worline: Resources, Resourcing, and Ampliative Cycles in Organizations, in: Oxford Handbook of Positive Organizational Scholarship, 2011, pp. 629-641.

21 D. Kahneman, A. Tversky: Prospect Theory: An Analysis of Decision under Risk, in: Econometrica, Vol. 47, 1979, p. 263. ample, the negative emotions associated with losses are significantly stronger than the positive emotions induced by resource gains of equal magnitude (i.e. loss aversion).

And while humans suffer from several such heuristics and biases in their economic decision-making (i.e. bounded rationality), ultimately, they still appear to tend to strive towards optimising their subjective expected utility (SEU). However, choices based on SEU (i.e. what people want or prefer) may not perfectly overlap with the options that satisfy people most in the end. Hence, recent research discusses experienced utility as a metric that more closely matches the concept of happiness that is also increasingly discussed as a standard for policy evaluation. ${ }^{22}$ Hence, the key research question for driving the digital transformation is: when does technology make us happy?

In fact, research on human-centred technology development has so far discussed several sociotechnical configurations where technology usage may induce happiness. For example, the paradigm of usability suggests that technology should be designed in such a manner that it simplifies resource regulation, thereby making goal achievement easier (i.e. technology that improves effectiveness, efficiency and satisfaction of achieving goals, cf. DIN EN ISO 9241).

This also includes the idea that, every metric of humancentred technology, has to take user diversity into account as a central design criterion. That is, user diversity goes beyond physiological differences between humans, e.g. brought about by age or accident - which often already comes into play when technology is optimized for accessibility. User diversity also comes in the form of psychological traits that affect the individual user-technology interaction styles. For example, users differ in their affinity for technological interaction, meaning whether a person tends to actively engage in technology interaction, or whether a person tends to avoid intensive interaction with technology. Obviously, the active engagement with technology can be a personal resource for users' successfully coping with ever new technologies (i.e. for the continuous adaptation to technology evolution and successful problem solving within the interaction with novel technological systems). ${ }^{23}$ Hence, by

22 S. Carter, M. McBride: Experienced utility versus decision utility: Putting the ' $S$ ' in satisfaction, in: The Journal of Socio-Economics, Vol. 42, 2013, pp. 13-23; D. Kahnemann, R. Sugden: Experienced Utility as a Standard of Policy Evaluation, in: Environmental and Resource Economics, Vol. 32, No. 1, 2005, pp. 161-181.

23 T. Franke, C. Attig, D. Wessel: A Personal Resource for Technology Interaction: Development and Validation of the Affinity for Technology Interaction (ATI) Scale, in: International Journal of Human-Computer Interaction, Vol. 35, No. 6, 2019, pp. 456-467. 
considering user diversity, digitalisation can benefit all members of a target audience.

However, the psychological model that lies behind the paradigm of usability (i.e. humans as cognitive problem solvers) may be too narrow and incomplete (i.e. may not account for the full variance in experienced happiness in human technology interaction). Further, while the paradigm of usability implies that, from a psychological perspective, technology can be best when it assists goal-oriented behaviour, this only describes the how and not the what of digitalisation. Hence, it does not help to answer the question which tools or functions should be digitalised, and which shouldn't. One could after all, simply digitalise everything in our lives.

One possible counterargument against the design rational behind the usability paradigm could be that a human is not just a bounded-rational homo economicus, who only consciously seeks to maximise expected or experienced utility. Instead, some fundamental goals or resource needs may not be salient at a given time or may not be a direct part of conscious goal-directed cognitive control, but may still be key for ensuring long-term happiness and a good quality of life. That is, humans may (sometimes) know what they want (i.e. the core variable assessed in user-centred design) but may not know (i.e. consciously represent) what they ultimately need.

Hence, one different perspective would be to focus technology development to best match basic human needs. The well-established Self-Determination Theory (SDT), for example, proposes three basic needs for humans to feel self-determined and self-motivated: ${ }^{24}$

1. Autonomy. A feeling of being in control of one's own behaviour and goals.

2. Relatedness. A sense of belonging/attachment to other people or a community.

3. Competence. A feeling of mastery of skills needed to achieve goals.

These three basic needs also received empirical support in more recent research that studied the link between ten candidate basic needs and situations related to positive affect (i.e. particularly satisfying events)..$^{25}$ This research

24 E. Deci, R. Ryan: Overview of Self-Determination Theory: An Organismic Dialectical Perspective, in: Handbook of Self-Determination Research, New York 2002, pp. 113-148.

25 K. Sheldon, A. Elliot, Y. Kim, T. Kasser: What Is Satisfying about Satisfying Events? Testing 10 Candidate Psychological Needs, in: Journal of Personality and Social Psychology, Vol. 80, No. 2, 2001, p. 325. also showed that the three needs proposed by SDT should be expanded upon by another:

4. Self-esteem. A feeling of being satisfied with one's self (i.e. with one's own worth).

Thus, is good digitalisation technology that which fulfils our needs for autonomy, relatedness, competence and self-esteem, within the process of reaching and retaining target states through resource regulation? Unfortunately, this model of humans may again be perceived as incomplete, as it only describes technology which has the maximum potential to become addictive (e.g. like social media platforms that provide a very powerful tool to create digital experiences that directly address and instantaneously satisfy such core human needs). Yet, the instantaneous satisfaction of human needs is lacking a stronger long-term perspective of intertemporal decision-making (i.e. intertemporal satisfaction or future utility). Also, the focus on individual experienced utility may not perfectly match the net societal utility of different possible pathways of digital innovations. Sustainability could define an alternative metric that addresses these problems.

\section{Sustainability as a compass for the digital} transformation

Looking at the net long-term utility of possible technological pathways (i.e. integrated current and future utility), it can be argued that fulfiling the desires of individuals or of a society at one specific point in time cannot be the optimal metric to guide digitalisation. Focusing solely on what can achieve current goals (such as e.g. maximising GDP, gross domestic product), does not account for the future goals of future generations. To underline this, an illustrative historic example can be used, which is most prominently displayed in the mountain altar of Saint Anne's Church in Annaberg, Saxony (see Figure 1). ${ }^{26}$

Due to thriving silver mining, the Ore Mountains (Erzgebirge) of Saxony were of great economic importance to the region. As a consequence, the local, primeval forest of Miriquidi shrunk drastically over the centuries, as massive amounts of wood were needed to extract silver from the mountains. 1645 nobleman Hans Carl von Carlowitz was born at Rabenstein Castle near today's city of Chemnitz. After several years of working within the mining administration of Saxony, he was finally appointed the chief mining officer of the Erzgebirge in 1711. As

26 UNESCO World Heritage Centre, Erzgebirge/Krušnohoří Mining Region. 2019, https://whc.unesco.org/en/list/1478/ (3.1.2020). 
Figure 1

Mountain Altar of Saint Anne's Church in Annaberg
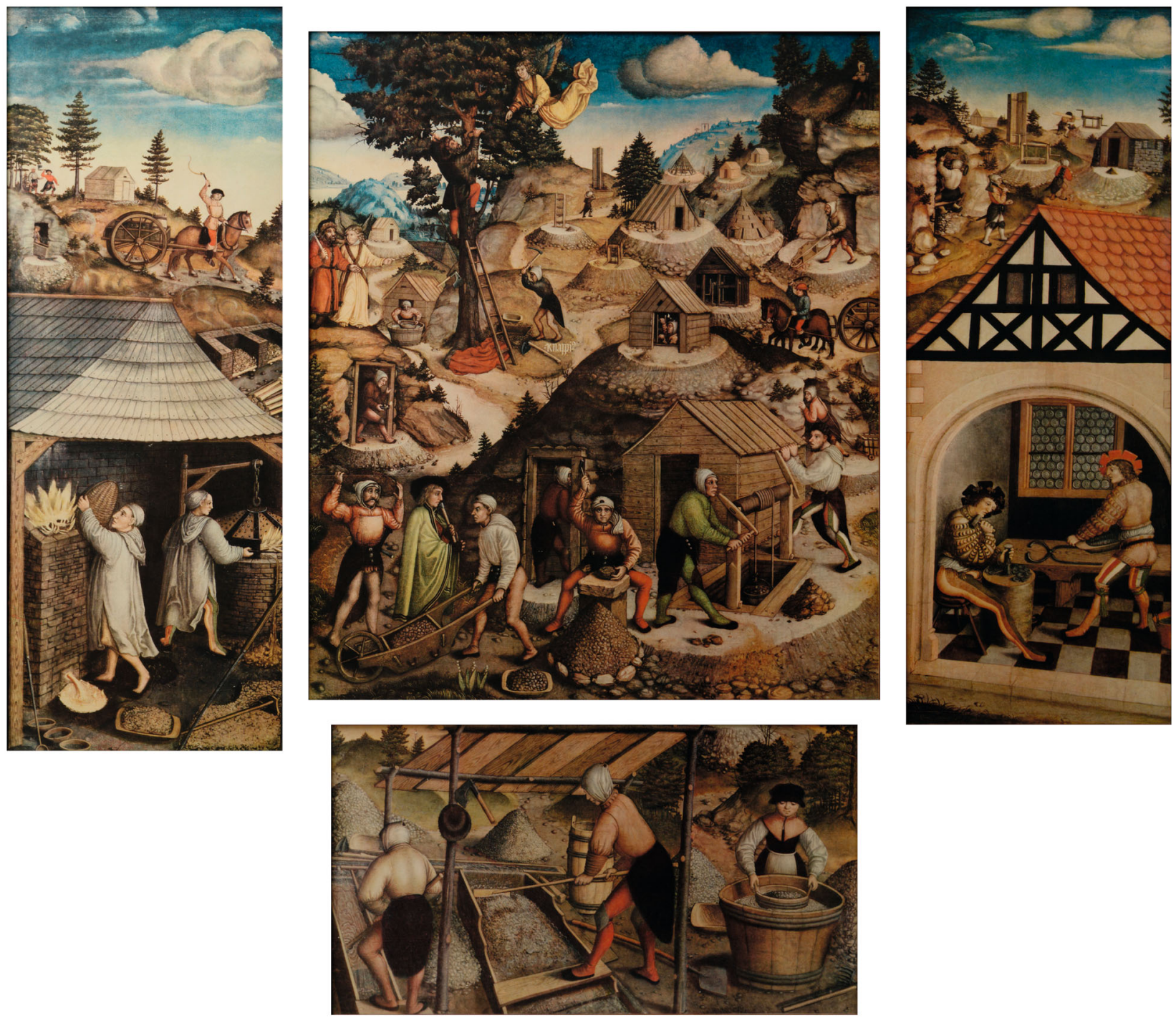

Source: Hans Hesse: Annaberger Bergaltar, 1522, Annaberg-Buchholz, https://de.wikipedia.org/wiki/Hans_Hesse_(Maler)\#/media/Datei:AnnabergerBergaltar2.jpg (25.2.2020).

head of the Saxon Upper Mining Authority in Freiberg, his responsibilities also included the supply of wood for the mining and metallurgical industries of the whole silver mining region of Saxony. In this position, he strongly criticised the unsustainable exploitation of the resource wood and the increasing deforestation. However, his criticism was not necessarily related to an environmentalist perspective, rather the resource wood carried (and still carries) the inherent economic necessity to conduct intertemporal resource regulation, because of the speed of replenishment of this renewable resource.
Carlowitz argued, that in order to maximise the yield of trees one should only harvest as many trees as can be regrown to satisfy future wood harvesting needs. Ultimately, his book on sustainable resource management, the "Sylvicultura Oeconomica“ (1713) laid the foundation for the field of sustainable yield forestry. And with this key work Hans Carl von Carlowitz is now acknowledged as the father of the modern concept of sustainability which is, in its essence, intertemporal (i.e. net long-term) experienced utility maximization, integrating utilities on economic, ecologic and social dimensions. 
This digression serves to make clear that good digitalisation, which has been shown to be integral to resource regulation, should more importantly support intergenerational resource regulation, thereby incorporating a focus on the long-term consequences of digitalisation. In other words, not only should the needs of an individual or a society at any given time be the central of focus of a navigation toolkit of a 'good' digital transformation, but rather the needs of all humans to come. That is, what we need is humanity-centred design.

\section{Conclusion}

By using examples of current and historical precedents, as well as outlines of psychological limitations and characteristics of human information processing and resource regulation, the present paper argued that unless humans are put into the centre of its design, digitalisation will be driven by innovation, potentially leading to the necessity of massive post-hoc corrections of negative outcomes and large associated societal costs (i.e. resource losses).

Instead, this paper suggests that technological innovations within the digital transformation should be driven and shaped centrally by society. Through the cooperation of all experts who foster digitalisation, including those who drive the social dialogue, the design of a navigation toolkit of good digitalisation could be enabled. We suggest that an ideal toolkit to drive the digital transformation should include models, metrics, performance indicators and simplification tools that allow for the management and monitoring of the direction and progress of a 'good' digital transformation. Further, we suggest a key model (i.e. target image) of good digitalisation as a goal-oriented resource regulation in fields that benefit the core human needs for competence, autonomy, relatedness and selfesteem, while accounting for user diversity and a perspective of intergenerational resource regulation in the pathway of sustainable development.

Future work should seek not only to institutionalise expert-based humanity-centred design, but also seek out approaches to further support societal cooperation in the course of the digital transformation, for example by empowering citizen scientists to become active parts of the community that drives this societal transformation as a process of the democratic co-design of our common digital future.

Title: Technology for the People? Humanity as a Compass for the Digital Transformation

Abstract: How do we define what technology is for humans? One perspective suggests that it is a tool enabling the use of valuable resources such as time, food, health and mobility. One could say that in its cultural history, humanity has developed a wide range of artefacts that enable the effective utilisation of these resources for the fulfilment of physiological, as well as psychological, needs. This paper explores how this perspective may be used as an orientation for future technological innovation. Hence, the goal is to provide an accessible discussion of such a psychological perspective on technology development that could pave the way towards a truly humancentred digital transformation.

JEL Classification: O330, 1310, B400 